Ley Orgánica 6/2012, de 30 de octubre, por la que se autoriza la ratificación por España del Tratado de Adhesión a la Unión Europea de la República de Croacia.

\author{
RAFAEL MARÍN AÍS \\ Profesor Contratado FPU \\ Derecho internacional público \\ Universidad de Granada
}

La adhesión de Croacia a la Unión Europea previsiblemente se hará efectiva a partir del 1 de julio de 2013, siempre y cuando los 27 Estados miembros actuales hayan ratificado con arreglo a sus respectivos órdenes constitucionales el Tratado de Adhesión, del mismo modo que España ha hecho ex artículo 93 de la Constitución Española. Croacia se convertirá así en el vigesimoctavo Estado miembro. El tratado que habilita a la adhesión ha sido firmado tan sólo veinte años después de que Croacia proclamara unilateralmente su independencia de la antigua República Federal Socialista de Yugoslavia, Estado que durante la Guerra Fría formó parte del Movimiento de Países No Alineados. Dicha condición la perdió la antigua Yugoslavia precisamente durante los cruentos conflictos armados que se sucedieron en los años siguientes y que finalizaron en un intento fallido por evitar su desmembración como Estado, que tuvo lugar en 1995. Eslovenia que proclamó su independencia de forma contemporánea a Croacia, fue el primer Estado de la antigua Yugoslavia en convertirse en miembro de la Unión en 2004. El resultado es de una elevada convergencia de Eslovenia en términos económicos con los quince Estados miembros de la Unión existentes antes de su incorporación. Las perspectivas no son hoy tan halagüeñas para Croacia, que de todos modos supera claramente en PIB per cápita (PPA) a Bulgaria o Rumanía, incorporadas en 2007, y que converge con otros Estados de Europa Central y Oriental miembros desde 2004 (Hungría o Letonia). Está por ver en qué medida Croacia mejorará su estatus con la adhesión en términos de lucha contra la corrupción, independencia del poder judicial o respeto a los derechos fundamentales, puesto que la experiencia de Bulgaria y Rumanía no es totalmente alentadora en este sentido y las medidas adoptadas hasta la fecha siguen siendo insuficientes. Las actuales Croacia y Eslovenia se corresponden con las regiones más ricas de la antigua Yugoslavia y ambas veían con recelo el excesivo poder en la federación de una Serbia menos dinámica: ambos países son los únicos de la antigua Yugoslavia que se han convertido a día de hoy en miembros de la OTAN. La escasa trayectoria de Croacia como Estado independiente así como las dificultades acentuadas por las que atraviesa el proyecto de integración supranacional europeo, especialmente en el terreno de la solidaridad territorial y financiera, ayudan a comprender la ausencia de un entusiasmo ferviente como cabría esperar por parte de la población croata ante esta coyuntura: efectivamente un aplastante $67 \%$ a favor de la incorporación a la Unión fue el resultado de la consulta popular, pero con unas débiles cifras de participación (44\%). Croacia con 4.5 millones de habitantes será uno de los Estados miembros con menor población, superando en volumen demográfico únicamente a los tres Estados bálticos, a la propia Eslovenia, a Luxemburgo, a Malta y a Chipre. Por tanto no supondrá una gran transformación desde el punto de vista del reparto de peso institucional en la Unión. Lo cierto es que la Unión Europea sigue ejerciendo un fuerte poder de atracción entre los países de la antigua Yugoslavia, sólo debe echarse un vistazo a la lista de candidatos oficiales a la adhesión: donde junto con la eterna aspirante Turquía y una Islandia con mayores visos de incorporarse, encontramos a tres Estados surgidos de la federación yugoslava, la Antigua República 
Yugoslava de Macedonia, Serbia y Montenegro (país éste último que emplea ya el Euro como moneda oficial). Albania, también ha solicitado ya su ingreso a la Unión y posiblemente lo hagan en el futuro Bosnia y Herzegovina y Kosovo, aunque no son candidatos oficiales a la adhesión. La Unión Europea ha concluido con todos estos Estados (el acuerdo con Serbia incluye a Kosovo) acuerdos de asociación y estabilización que implican un ambicioso trasvase a los mismos del acervo comunitario que incluye el respeto a los derechos fundamentales, a los principios democráticos y del Estado de Derecho y a las reglas de la economía de mercado y la libre competencia. El grado de compromiso que exigen estos acuerdos internacionales, comparado con los acuerdos que vehiculizaron las anteriores ampliaciones de 2004 y 2007, hace presagiar que la incorporación de los Estados de los Balcanes se demorará en el tiempo, hasta que la Unión pueda digerir adecuadamente sus últimas ampliaciones. De momento es innegable que a través de estos acuerdos y de la estrategia de la Comisión Europea, que pretende la incorporación en última instancia de todos estos Estados a la Unión incluyendo a Kosovo-, la Unión Europea está contribuyendo a incrementar la cooperación regional y a facilitar la reconciliación de una región que hace poco más de una década atrás vivía terribles episodios de depuración étnica. En esta región, escenario presente como pocos del crisol de civilizaciones e imperios que han intentado consolidar su dominio sobre el continente europeo, la exigencia de la Unión Europea a Serbia de normalizar sus relaciones con Kosovo como vía para la incorporación constituye una muestra de esta importante labor. Por su parte en el camino hacia su adhesión, Croacia ha tenido, a instancia de la Unión y mediante arbitraje, que llegar a un acuerdo para resolver una controversia de delimitación de los espacios marítimos con la vecina Eslovenia en la bahía de Pirán, donde ambos Estados venían disputándose un espacio que serviría a Eslovenia de corredor para lograr acceso a aguas internacionales del Adriático. Al igual que para Serbia es hoy una condición para la incorporación a la Unión la cooperación con el Tribunal Penal Internacional para la Antigua Yugoslavia, con sede en la Haya, lo fue en su día para Croacia; de hecho la entrega del general Ante Gotovina al Tribunal en 2005 supuso un antes y un después en las negociaciones de la adhesión, pues a partir de ese momento se reconoció la voluntad de Croacia de cooperar con el Tribunal. El general que fue condenado en 2011 a 24 años de prisión por la persecución, deportación, destrucción, saqueo contra la población serbia de Krajina, había sido detenido curiosamente en la isla de Tenerife en 2005.

Por otra parte, la adhesión de Croacia no entrañará una aplicación automática e inmediata de todo el acervo de la Unión, se establecen periodos transitorios: por ejemplo, durante los dos años siguientes a la adhesión los restantes Estados miembros podrán regular mediante acuerdos bilaterales el acceso de los nacionales croatas a sus mercados de trabajo, siendo únicamente de aplicación inmediata el desplazamiento temporal de trabajadores a los efectos de la prestación de servicios. Transcurrido dicho periodo, los Estados miembros deberán indicar a la Comisión si mantienen dichos acuerdos o si reconocen a los trabajadores croatas la libre circulación dentro de la Unión. Tampoco será de aplicación inmediata en Croacia la totalidad del llamado acervo Schengen, cuya aplicación plena estará sujeta a la decisión del Consejo de la Unión, y que será independiente de la que se adopte en relación con Bulgaria, Rumanía o Chipre que aún no reúnen a juicio del Consejo las condiciones para la supresión de los controles fronterizos interiores (recuérdese que Reino Unido e Irlanda siguen fuera por voluntad propia, y que en cambio, participan de este sistema Noruega, Liechtenstein, Suiza e Islandia). Además, Croacia podrá mantener en vigor durante un periodo de siete años una restricción a la adquisición de tierras agrícolas por parte de nacionales de otro Estado miembro, de nacionales de los Estados que sean parte en el Acuerdo sobre el 
Espacio Económico Europeo y de personas jurídicas constituidas de conformidad con la legislación de otro Estado miembro o de un Estado que sea parte en el Acuerdo sobre el Espacio Económico Europeo. En cualquier caso, durante el periodo transitorio dichas restricciones no podrán agravarse en relación a las existentes en el momento de firmarse el tratado de adhesión, ni tampoco podrá otorgarse un trato menos favorable que el dispensado a nacionales o personas jurídicas de terceros países ajenos tanto a la Unión como al Espacio Económico Europeo.

Croacia para ser elegida como candidato a la adhesión debía observar los criterios de elegibilidad fijados por el Consejo Europeo de Copenhague en 1993: se trata de criterios políticos (democracia, derechos humanos, Estado de derecho y protección de las minorías nacionales) y criterios económicos (fundamentalmente el respeto a las reglas de la economía de mercado). Actualmente, el artículo 49 del Tratado de la Unión Europea (TUE) se refiere a estos criterios de elegibilidad, en tanto el Consejo Europeo no adopte otros, así como al respeto a los valores fundacionales de la Unión (artículo 2 TUE), como requisitos ineludibles para solicitar el ingreso a la Unión Europea y obtener el estatuto de candidato. Para la obtención del estatuto de candidato el Consejo de la Unión debe pronunciarse por unanimidad tras haber consultado a la Comisión Europea y haber obtenido la aprobación del Parlamento Europeo. Después de un complejo proceso de negociaciones estructuradas en capítulos (31 para Bulgaria y Rumanía, 35 para Croacia o Turquía, por ejemplo) donde la Comisión Europea tiene un peso esencial, se llega a un tratado internacional para la adhesión entre el aspirante al ingreso y el resto de Estados miembros: dicho acuerdo internacional debe ser ratificado por todos los Estados miembros y por el propio solicitante de acuerdo con sus normas constitucionales para entrar en vigor. La exigencia doble de unanimidad, haría que, por ejemplo, una Cataluña que lograra la independencia de facto del Estado español no llegase a ser ni tan siquiera candidato a la adhesión a la Unión Europea. En cualquier caso, el tortuoso proceso de ampliación levanta suspicacias sobre diferentes raseros o posibles apreciaciones de los criterios para la adhesión con mayor o menor rigor o laxitud en función del candidato: Turquía constituye un buen ejemplo, y, amén del conflicto relativo al Norte de Chipre, no puede dejarse de ver que la ampliación a Turquía supondría la extensión de las fronteras exteriores de la Unión a países como Irak, Irán o Siria; además, Turquía sería un Estado miembro que tendría en las instituciones un peso equiparable al de Alemania. Reino Unido es un partidario de la ampliación, ya que considera que la misma está reñida con la profundización: lo cierto es que es deseable un equilibrio en esta dicotomía, y la Unión Europea tiene el reto hacia el interior no sólo de ser más que un mercado interior y de consolidar su Unión Económica y Monetaria, sino que además tiene la oportunidad de contribuir significativamente a la estabilización definitiva de la región de los Balcanes Occidentales, otrora lamentablemente olvidada. 


\section{DISPOSICIONES GENERALES}

\section{JEFATURA DEL ESTADO}

13486 Ley Orgánica 6/2012, de 30 de octubre, por la que se autoriza la ratificación por España del Tratado de Adhesión a la Unión Europea de la República de Croacia.

\section{JUAN CARLOS I}

\section{REY DE ESPAÑA}

A todos los que la presente vieren y entendieren.

Sabed: Que las Cortes Generales han aprobado y Yo vengo en sancionar la siguiente ley orgánica.

Con la firma en Bruselas, el 9 de diciembre de 2011, del Tratado de Adhesión de la República de Croacia a la Unión Europea, culmina un proceso negociador, iniciado en el año 2005, para la integración de dicho país en la Unión Europea.

De conformidad con lo previsto en el artículo 93 de la Constitución española, resulta necesario que la prestación del consentimiento del Estado para ratificar el referido Tratado de adhesión sea autorizada mediante Ley Orgánica, tal como ocurrió con motivo de la adhesión de la República Checa, la República de Estonia, la República de Chipre, la República de Letonia, la República de Lituania, la República de Hungría, la República de Malta, la República de Polonia, la República de Eslovenia y la República Eslovaca o con la posterior adhesión de la República de Bulgaria y la República de Rumanía a la Unión Europea.

Artículo único.

Se autoriza la ratificación por el Reino de España del Tratado hecho en Bruselas el 9 de diciembre de 2011 de Adhesión a la Unión Europea de la República de Croacia.

Disposición final única.

La presente Ley Orgánica entrará en vigor el día siguiente al de su publicación en el «Boletín Oficial del Estado».

Por tanto,

Mando a todos los españoles, particulares y autoridades, que guarden y hagan guardar esta ley orgánica.

Madrid, 30 de octubre de 2012.

JUAN CARLOS R.

El Presidente del Gobierno,

MARIANO RAJOY BREY 